https://doi.org/10.22319/rmcp.v10i3.4825

Artículo

\title{
Factores de riesgo a nivel de establo asociados con el desempeño reproductivo en el sistema de producción de leche a pequeña escala en México
}

Luis Javier Montiel-Olguín a,b

Eliab Estrada-Cortés ${ }^{c}$

Mario Alfredo Espinosa-Martínez ${ }^{a}$

Miguel Mellado $^{\mathrm{d}}$

Josafath Omar Hernández-Vélez ${ }^{\mathrm{e}}$

Guillermina Martínez-Trejo ${ }^{\mathrm{f}}$

Laura Hérnández-Andrade ${ }^{g}$

Rubén Hernández-Ortíz ${ }^{\text {h }}$

Arcelia Alvarado-Islas ${ }^{g}$

Felipe J. Ruiz-López ${ }^{\text {a }}$

Héctor Raymundo Vera-Avila ${ }^{\text {a,* }}$

${ }^{a}$ Instituto Nacional de Investigaciones Forestales, Agrícolas y Pecuarias (INIFAP). CENID Fisiología y Mejoramiento Animal, km.1 Carretera a Colón, 76280, Ajuchitlán, Colón, Querétaro, México.

${ }^{\mathrm{b}}$ Universidad Autónoma de Querétaro. Facultad de Ciencias Naturales. Querétaro, México.

${ }^{\mathrm{c}}$ INIFAP. Campo Experimental Centro Altos de Jalisco. Jalisco, México.

${ }^{\mathrm{d}}$ Universidad Autónoma Agraria Antonio Narro. Departamento de Nutrición Animal. Coahuila, México.

${ }^{\mathrm{e}}$ INIFAP· Campo Experimental San Martinito. Puebla, México.

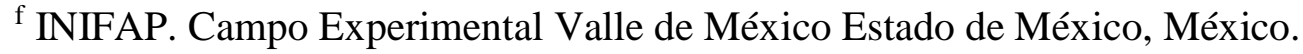

g INIFAP. CENID Salud Animal e Inocuidad. Ciudad de México, México.

${ }^{\text {h }}$ INIFAP. CENID Salud Animal e Inocuidad. Morelos, México.

* Autor de correspondencia: hrvera56@ gmail.com 


\section{Resumen:}

La rentabilidad de los establos lecheros está fuertemente asociada con el desempeño reproductivo. Por lo tanto, la identificación de factores de riesgo que comprometen este desempeño es primordial para implementar estrategias que mejoren la productividad. En este estudio, se probaron los efectos del uso de inseminación artificial (IA), hatos grandes y seroprevalencia alta de enfermedades infecciosas reproductivas sobre el desempeño reproductivo. Se incluyeron al estudio 52 establos (10-100 vacas; 959 lactaciones) registrando eventos reproductivos durante 18 meses (partos 2011-2012). Las seroprevalencias de neosporosis, rinotraqueitis infecciosa bovina (IBR) y diarrea viral bovina (BVD) se registraron en cada establo. Se utilizaron análisis de regresión logística múltiples para determinar el grado de asociación (razón de momios, OR) entre factores potenciales de riesgo y variables reproductivas. Establos $\geq 33$ vacas y seroprevalencia alta de neosporosis fueron factores de riesgo para Asistencia al Parto (OR 1.5 y 2.3, respectivamente). Seroprevalencias altas de IBR y BVD fueron factores de riesgo para Días a Primer Servicio>70 Días en Leche (DPS>70, OR 1.3 y 1.9, respectivamente). La IA fue un factor de riesgo común para DPS>70 y Días Abiertos>110 Días en Leche (OR 2.4 y 1.3, respectivamente). Establos $\geq 33$ vacas fue un factor de riesgo para Vacas No Gestantes al Primer Servicio (OR 1.7). En conclusión, la IA, establos $\geq 33$ vacas y seroprevalencias altas de neosporosis, IBR y BVD son factores asociados al desempeño reproductivo en establos de producción de leche a pequeña escala en varias regiones geográficas de México.

Palabras clave: Inseminación artificial, Factores de riesgo, Neosporosis, BVD, IBR.

Recibido: 27/03/2018

Aceptado:21/08/2018

\section{Introducción}

Los sistemas de producción de leche a pequeña escala mejoran la seguridad alimentaria y proporcionan ingresos económicos en zonas rurales a nivel mundial ${ }^{(1)}$. En México, este sistema de producción posee aproximadamente el $23 \%$ del inventario ganadero ${ }^{(2)}$, contribuye con el $30 \%$ de la producción nacional de $\operatorname{leche}^{(3)}$ y representa el $73 \%$ de los establos lecheros ${ }^{(4)}$. Las unidades de producción en este sistema se caracterizan por incorporar mano de obra familiar, utilizan en mayor medida razas especializadas en la producción de leche, tienen pocos vientres en producción y niveles medios-bajos de tecnificación ${ }^{(5-7)}$. La mejora productiva de estos establos lecheros a pequeña escala contribuye a disminuir la pobreza en zonas rurales $^{(1)}$, y promover el desarrollo de las comunidades ${ }^{(8,9)}$.

La rentabilidad de los establos lecheros está fuertemente asociada con el desempeño reproductivo eficiente ${ }^{(10,11)}$. La identificación de factores de riesgo que comprometen el desempeño reproductivo es primordial para diseñar e implementar estrategias que mejoren 
la productividad. Existen estudios en hatos de producción de leche a pequeña escala que indican que la IA puede afectar el intervalo parto a primer servicio postparto y la tasa de concepción por servicio en comparación con la monta directa ${ }^{(12,13)}$. Además, en sistemas intensivos de producción se ha observado que el tamaño de hato influye sobre el desempeño reproductivo ${ }^{(14-16)}$, al igual que el nivel de seroprevalencia de enfermedades infecciosas reproductivas como neosporosis, rinotraqueitis infecciosa bovina (IBR) y diarrea viral bovina $(B V D)^{(17,18)}$. Por lo tanto, el objetivo del presente trabajo fue determinar el impacto, como factores potenciales de riesgo a nivel de establo, del uso de IA, tamaño del hato y prevalencia de enfermedades infecciosas reproductivas sobre el desempeño reproductivo en establos productores de leche a pequeña escala en México. La hipótesis de trabajo fue que estos factores están asociados con el desempeño reproductivo en vacas lecheras.

\section{Material y métodos}

\section{Selección de establos y registro de la información}

Se llevó a cabo un estudio de cohorte prospectivo observacional (959 registros) en seis estados de México donde el sistema de producción de leche a pequeña escala tiene presencia importante. Se incluyeron al estudio 52 establos con la siguiente distribución por estado: Jalisco (23), Estado de México (10), Tlaxcala (9), Guanajuato (4), Puebla (3), y Querétaro (3). Los criterios de selección utilizados fueron los siguientes: soporte primario de mano de obra familiar en la unidad de producción, que contaran con un número de vientres en producción entre 10 y 100, que la producción de leche fuera el objetivo primario del establo y que el nivel de incorporación de tecnología fuera medio-bajo. El porcentaje de vacas Holstein y el número promedio de vacas en los establos fueron $91.3 \%$ y $30.3 \pm 2.4$, respectivamente. La tasa estimada de desecho y la producción de leche por vaca fueron $26.4 \%$ y $17.10 \pm 0.5 \mathrm{~kg} /$ día, respectivamente. Los establos incorporados al estudio cumplen características de establos de producción a pequeña escala en México descritos en otras publicaciones ${ }^{(2,7,19)}$. El periodo de captura de información a nivel de campo fue durante 18 meses, periodo en el que se registraron los siguientes eventos reproductivos: fechas de parto, fechas y tipo de servicios (inseminación artificial o monta directa), ocurrencia de asistencias al parto o retenciones de placenta, y resultado de diagnóstico de gestación alrededor de 50 días post-servicio. 


\section{Eventos de interés y clasificación de factores potenciales de riesgo relacionados con el desempeño reproductivo}

Los eventos de interés considerados fueron: asistencia al parto (asistencia menor y asistencia mayor en la misma categoría), retención de placenta $(>12 \mathrm{~h})$, días a primer servicio mayor a 70 días en leche (DPS>70), días abiertos mayores a 110 días en leche (DA>110) y vacas no gestantes al primer servicio (NG1S). Con base a lo que se ha sugerido para el sistema de producción de leche a pequeña escala se establecieron los valores límite >70 DPS y >110 DA como indicadores de falla reproductiva ${ }^{(19)}$.

Los factores potenciales de riesgo incluyeron al uso de la IA, hatos grandes y seroprevalencias altas de neosporosis, IBR y BVD. Para clasificar los establos por tipo de servicio, se consideraron en la categoría IA a aquellas unidades de producción donde al menos $75 \%$ de los servicios fueron brindados utilizando esta tecnología y en la categoría de monta natural cuando al menos el $75 \%$ de los servicios se proporcionó por monta natural. Los límites para tamaño del hato y seroprevalencias se establecieron de acuerdo con la distribución por cuartiles en la muestra de estudio ${ }^{(20)}$. La clasificación del tamaño de hato se hizo con base en el número de vientres en producción promedio por establo durante el periodo de captura de información a nivel de campo; el tercer cuartil correspondió a 33 vacas (clasificación $<33$ o $\geq 33$ ). El tercer cuartil se estableció como límite para clasificar a los establos con seroprevalencia alta; neosporosis ( $\geq 84 \%)$, IBR ( $\geq 38 \%)$ y BVD (=100 \%) (Cuadro 1).

\section{Identificación de animales seropositivos a neosporosis, IBR y BVD}

Se colectaron muestras de sangre por punción de vena coccígea (sistema vacutainer), de forma aleatoria en el $10 \%$ de las vacas en producción en cada hato en estudio. Las muestras de sangre fueron mantenidas a $4{ }^{\circ} \mathrm{C}$ por $24 \mathrm{~h}$, posteriormente fueron centrifugadas $(2,500 \mathrm{xg}$ por 10 min a $4{ }^{\circ} \mathrm{C}$ ) para separar el suero, el cual fue congelado a $-20^{\circ} \mathrm{C}$ hasta su análisis.

La detección de anticuerpos contra Neospora caninum se realizó mediante la prueba de ELISA utilizando un kit comercial (Laboratorios IDEXX), de acuerdo con las instrucciones del fabricante. El análisis de los sueros para DVB se realizó con un kit comercial de ELISA por bloqueo (CIVTEST bovis BVD/Bd P80, Laboratorios Hipra), siguiendo las instrucciones del fabricante. El análisis de IBR se realizó mediante la técnica de seroneutralización en placa, empleando la línea celular MDBK (células de riñón de bovino) y el virus de Referencia IBR758, con título de $10^{5.6}$ TCID ${ }^{50 \%}$ a una dilución entre 500-1000 dosis infectante/ml. Los sueros se diluyeron de 1:2 hasta 1:128 y se observó el efecto citopático producido por el virus para determinar la muestra como positiva ${ }^{(18)}$. No se contó con historial de vacunación en cada unidad de producción, sin embargo, en las regiones estudiadas esta práctica es común ${ }^{(13,18)}$. 


\section{Análisis estadístico}

Todos los análisis fueron llevados a cabo utilizando el paquete estadístico SAS 9.3 (SAS Institute Inc., Cary, NC). Para identificar a los factores de riesgo se utilizaron análisis de regresión logística múltiple (PROC LOGISTIC) siguiendo la metodología implementada por Potter $e t a l^{(21)}$. Para elaborar estos modelos, el primer paso fue realizar pruebas de regresión logística simple entre los eventos de interés y los factores potenciales de riesgo. Los factores con un valor de $P<0.35$ fueron retenidos y analizados posteriormente para colinealidad ${ }^{(21)}$. Para prevenir colinealidad en los modelos múltiples, se obtuvieron coeficientes de correlación y se aplicaron pruebas de $\chi 2$ en pruebas pareadas de factores retenidos utilizando el procedimiento FREQ opción CHISQ. Cuando en un par de factores, el límite de confianza del coeficiente de correlación no incluyó al 0 y el valor de $P$ de $\chi^{2}$ fue $<0.05$, ambas variables no fueron incluidas en el mismo modelo múltiple. Finalmente, con el objetivo de obtener modelos múltiples parsimoniosos, se utilizó la opción BACKWARD para retener variables

significativas a un valor de $P<0.1^{(21)}$. Los modelos múltiples finales incluyeron únicamente a los efectos principales y la razón de momios (OR) fue utilizada como una medida de asociación entre los factores de riesgo y las variables de interés.

\section{Resultados}

\section{Eventos de interés y factores potenciales de riesgo a nivel de establo relacionados con el desempeño reproductivo}

Estadísticas descriptivas para eventos de interés. Las prevalencias de los eventos de interés asistencia al parto y retención de placenta fueron 13.2 y $11.7 \%$ respectivamente. La proporción de vacas con DPS>70, DA>110 y NG1S fueron 64.9, 46.4 y $50.5 \%$ respectivamente.

Factores potenciales de riesgo. Los establos con el factor potencial de riesgo IA representaron el $73.9 \%$, mientras que los clasificados con tamaño $\geq 33$ vacas representaron el $41.3 \%$. En el Cuadro 1 se muestra la distribución de seroprevalencias para neosporosis, IBR y BVD.

\section{Factores de riesgo asociados a la falla en el desempeño reproductivo}

El nivel de significancia y las razones de momios obtenidos en los análisis de regresión logística simple se muestran en el Cuadro 2. En el Cuadro 3 se muestran los modelos múltiples para cada evento de interés. Para la variable de interés asistencia al parto, los factores de riesgo identificados $(P<0.10)$ fueron establos con $\geq 33$ vacas y seroprevalencia alta de neosporosis (Cuadro 4). Con respecto a la variable de interés retención de placenta, no se detectaron 
factores de riesgo $(\mathrm{OR}>1)$. Sin embargo, IA y seroprevalencia alta de IBR fueron factores significativos (OR $<1, P<0.10$; Cuadro 4). Para la variable de interés DPS $>70$ los factores de riesgo identificados fueron IA y seroprevalencias altas de IBR y BVD $(P<0.10$; Cuadro 5). Con relación a la variable de interés DA $>110$, la IA fue el único factor de riesgo identificado $(P<0.10$; Cuadro 5). Para la variable de interés NG1S, establos $\geq 33$ vacas fue el único factor de riesgo identificado $(P<0.10)$.

Cuadro 1: Seroprevalencias para neosporosis, rinotraqueítis infecciosa bovina (IBR) y diarrea viral bovina (BVD) en 52 establos de producción de leche a pequeña escala

\begin{tabular}{lllllll}
\hline & Media \pm EE & Mínimo & Cuartil 1 & Mediana & $\begin{array}{l}\text { Cuartil } \\
\mathbf{3}\end{array}$ & Máximo \\
\hline Neosporosis & $52.7 \pm 4.5$ & 0 & 33 & 50 & 84 & 100 \\
IBR & $23.3 \pm 1.8$ & 0 & 0 & 23.5 & 38 & 75 \\
BVD & $59.7 \pm 3.2$ & 0 & 28 & 75 & 100 & 100 \\
\hline
\end{tabular}

Cuadro 2: Valor de probabilidad $(P)$ y razón de momios $(\mathrm{OR})$ para factores potenciales de riesgo considerando diferentes eventos de interés; análisis de regresión logística simple

\begin{tabular}{lccccc}
\hline \multicolumn{7}{c}{ Eventos de interés } & & & \\
\hline \multicolumn{1}{c}{ Factores } & AP $(\mathbf{P} ; \mathbf{O R})$ & RP $(\mathbf{P} ; \mathbf{O R})$ & $\begin{array}{c}\text { DPS }>\text { 70 } \\
(\mathbf{P} ; \mathbf{O R})\end{array}$ & $\begin{array}{c}\text { DA>110 } \\
(\mathbf{P} ; \mathbf{O R})\end{array}$ & $\begin{array}{c}\text { NG1S } \\
(\mathbf{P} ; \mathbf{O R})\end{array}$ \\
\hline IA & $0.048 ; 0.67$ & $0.072 ; 0.68$ & $<0.001 ; 2.39$ & $0.054 ; 1.32$ & $0.162 ; 0.82$ \\
Establos $\geq 33$ vacas & $0.090 ; 1.52$ & $0.821 ; \mathrm{NC}$ & $0.853 ; \mathrm{NC}$ & $0.823 ; \mathrm{NC}$ & $0.001 ; 1.69$ \\
Neosporosis alta & $<0.001 ; 2.29$ & $0.099 ; 0.64$ & $0.414 ; \mathrm{NC}$ & $0.357 ; \mathrm{NC}$ & $0.718 ; \mathrm{NC}$ \\
IBR alta & $0.202 ; 1.32$ & $0.005 ; 0.42$ & $0.169 ; 1.25$ & $0.484 ; \mathrm{NC}$ & $0.916 ; \mathrm{NC}$ \\
BVD alta & $0.010 ; 0.46$ & $0.793 ; \mathrm{NC}$ & $<0.001 ; 1.86$ & $0.553 ; \mathrm{NC}$ & $0.049 ; 0.72$ \\
\hline
\end{tabular}

$\mathrm{IA}=$ inseminación artificial; $\mathrm{AP}=$ asistencia al parto; $\mathrm{RP}=$ retención placentaria; $\mathrm{DPS}>70=$ días a primer servicio mayor a 70 días en leche; $\mathrm{DA}>110=$ días abiertos mayores a 110 días en leche;

$\mathrm{NG1S}=$ vacas no gestantes al primer servicio; $\mathrm{NC}=$ indica OR no calculado por no ser significativo. 
Cuadro 3: Factores potenciales de riesgo no colineales para eventos de interés incluidos en modelos múltiples

\begin{tabular}{lll}
\hline Evento de interés & Modelo & Factores potenciales de riesgo \\
\hline Asistencia al parto & 1 & IA + IBR Alta \\
& 2 & Establos $\geq 33$ vacas + Neosporosis alta \\
& 3 & BVD alta \\
Retención placentaria & 1 & IA + Neosporosis alta \\
& 2 & IA + IBR alta \\
DPS $>70$ días & 1 & IA + IBR alta \\
& 2 & BVD alta + IBR alta \\
DA>110 & 1 & IA \\
NG1S & 1 & Establos $\geq 33$ vacas \\
& 2 & BVD alta \\
& 3 & IA \\
\hline
\end{tabular}

DPS $>70=$ días a primer servicio mayor a 70 días en leche; DA $>110=$ días abiertos mayores a 110 días en leche; NG1S= vacas no gestantes al primer servicio; IA= inseminación artificial; $\mathrm{BVD}=$ diarrea viral bovina; $\mathrm{IBR}=$ rinotraqueitis infecciosa bovina.

Cuadro 4: Efecto de variables de estudio sobre asistencia al parto y retención de placenta en modelos múltiples

\begin{tabular}{lllll}
\hline Variable de interés & Efectos & OR & IC 95\% & $P$
\end{tabular}

Asistencia al parto

Modelo 1

Tipo de servicio: MN

Ref. N/A

N/A

Tipo de servicio: IA

$0.67 \quad 0.45-0.99$

0.048

Modelo 2

Tamaño del hato: $<33$ vacas

Ref. N/A

N/A

Tamaño del hato: $\geq 33$ vacas

$\begin{array}{lll}1.51 & 0.90-2.45 & 0.090\end{array}$

Neosporosis: Resto

Ref. N/A

N/A

Neosporosis: Alta

$2.28 \quad 1.52-3.40$

$<0.001$

Modelo 3

BVD: Resto

Ref. N/A

N/A

BVD: Alta

$0.46 \quad 0.26-0.83$

0.010

Retención placentaria 


\begin{tabular}{lllll}
\hline Modelo 1 & Tipo de servicio: $\mathrm{MN}$ & Ref. & N/A & N/A \\
& Tipo de servicio: IA & 0.68 & $0.45-1.04$ & 0.072 \\
Modelo 2 & Ref. & N/A & N/A \\
& Tipo de servicio: MN & 0.66 & $0.43-1.01$ & 0.055 \\
& IBR: Resto & Ref. & N/A & N/A \\
& IBR: Alta & 0.41 & $0.23-0.75$ & 0.004 \\
\hline
\end{tabular}

$P=$ valor de probabilidad; $\mathrm{MN}=$ monta natural; $\mathrm{IA}=$ inseminación artificial; $\mathrm{BVD}=$ diarrea viral bovina; $\mathrm{IBR}=$ rinotraqueítis infecciosa bovina; $\mathrm{IC}=$ intervalo de confianza de razón de momios; $\mathrm{OR}=$ razón de momios; N/A= no aplicable.

Cuadro 5: Efecto de variables de estudio sobre días a primer servicio (DPS > 70), días abiertos $(\mathrm{DA}>110)$ y no gestante al primer servicio (NG1S) con diferentes modelos múltiples

\begin{tabular}{lllll}
\hline Variable de interés & Efectos & OR & IC 95\% & $\boldsymbol{P}$ \\
\hline DPS $>$ 70 & & & & \\
Modelo 1 & Tipo de servicio: MN & Ref. & N/A & N/A \\
& Tipo de servicio: IA & 2.04 & $1.81-3.2$ & $<0.001$ \\
& IBR: Resto & Ref. & N/A & N/A \\
& IBR: Alta & 1.32 & $0.95-1.84$ & 0.097 \\
Modelo 2 & BVD: Resto & Ref. & N/A & N/A \\
& BVD: Alta & 1.86 & $1.31-2.64$ & $<0.001$ \\
DA>110 & & & & \\
Modelo 1 & Tipo de servicio: MN & Ref. & N/A & N/A \\
NG1S & Tipo de servicio: IA & 1.32 & $0.99-1.8$ & 0.054 \\
Modelo 1 & & & & \\
& Tamaño del hato: $<33$ vacas & Ref. & N/A & N/A \\
Modelo 2 & Tamaño del Hato: $\geq 33$ vacas & 1.69 & $1.23-2.32$ & 0.001 \\
& BVD: Resto & Ref. & N/A & N/A \\
& BVD: Alta & 0.72 & $0.25-1.00$ & 0.049
\end{tabular}

$\mathrm{P}=$ valor de probabilidad; $\mathrm{IC}=$ intervalo de confianza de razón de momios; $\mathrm{MN}=$ monta natural; $\mathrm{IA}=$ inseminación artificial; $\mathrm{BVD}=$ diarrea viral bovina; $\mathrm{IBR}=$ rinotraqueitis infecciosa bovina; $\mathrm{OR}=$ razón de momios; N/A= no aplicable. 


\section{Discusión}

El sistema de producción de leche a pequeña escala en México es altamente heterogéneo en cuanto a manejo productivo, reproductivo y estatus sanitario ${ }^{(13,19)}$. Desde un punto de vista sanitario, neosporosis, IBR y BVD son enfermedades asociadas a desórdenes reproductivos $^{(22,23)}$. En el presente estudio, la media en seroprevalencias para neosporosis por establo representó valores similares a lo reportado previamente para el sistema de producción de leche a pequeña escala $(51.7 \%)^{(24)}$. Sin embargo, es mayor a lo reportado para el sistema intensivo en México $(\sim 43 \%)^{(18,25)}$. Es probable que las medidas de bioseguridad sean menos estrictas en los establos de producción de leche a pequeña escala, lo cual pudiera estar incrementando factores de riesgo asociados a la presencia de Neospora, como la presencia de perros en las unidades de producción ${ }^{(26,27)}$. Por otra parte, la seroprevalencia de IBR en el presente estudio fue similar a lo reportado previamente en el sistema de producción de leche a pequeña escala en México con tasas que rondan el $22 \%{ }^{(24,28)}$. Sin embargo, algunos estudios han reportado hasta el $69 \%$ de seroprevalencia en el sistema de producción a pequeña escala ${ }^{(18)}$. Referente a BVD, la seroprevalencia promedio obtenida por establo se encuentra en un punto medio entre lo reportado para este sistema de producción $(52-81 \%)^{(18,24)}$. Anteriormente se ha propuesto que estas enfermedades son endémicas y con alta prevalencia en ganado lechero en los sistemas intensivo, doble propósito y a pequeña escala en México ${ }^{(18,29,30)}$. A pesar de que las altas seroprevalencias encontradas pudieran deberse a anticuerpos vacunales para IBR y BVD, estos resultados confirman la importancia de estas enfermedades reproductivas en establos de producción a pequeña escala debido a su diseminación sobre una gran área o distancia, y alta prevalencia de estas enfermedades.

Hasta donde tenemos conocimiento, este es el primer trabajo que reporta factores de riesgo a nivel de establo asociados con el desempeño reproductivo en el sistema de producción de leche a pequeña escala en México. Los establos con seroprevalencia alta de neosporosis y establos con 33 o más vacas tuvieron 128 y $51 \%$ respectivamente, más probabilidad de requerir asistencia al parto. Estos resultados son consistentes con reportes previos sobre una asociación significativa entre asistencia al parto y animales seropositivos a Neospora ${ }^{(31)}$. Sin embargo, otros estudios no han encontrado esta asociación ${ }^{(32)}$, por lo tanto, son necesarios más estudios para clarificar esta asociación potencial. La asistencia al parto fue más prevalente en establos $\geq 33$ vacas. Una posible explicación es que en establos más grandes utilicen sementales (IA o monta natural) de mayor talla, o bien que existan problemas asociados a la condición corporal al parto, hipótesis pendiente de ser desafiada. Otra explicación radica en que, en este sistema de producción, el productor y su familia se hacen cargo personalmente de toda la operación del establo y del campo ${ }^{(6)}$. Por otra parte, se ha reportado que el manejo en el periparto de la vaca y la atención obstétrica correcta son algunos de los principales factores a considerar para controlar los problemas de $\operatorname{distocia}^{(33)}$. Es razonable pensar que, debido a las múltiples tareas del productor, él y los miembros de su familia son incapaces de proveer adecuado cuidado durante el parto en stablos $\geq 33$ vacas. 
Por otra parte, los animales en los establos con mayor prevalencia de BVD y lo s establos que utilizan IA tienen un menor riesgo de asistencia al parto. Este resultado era esperado, en otros estudios se ha reportado que el peso al nacimiento de becerros positivos a antígenos de BVD son $7 \mathrm{~kg}$ más ligeros que su contraparte de becerros negativos ${ }^{(34)}$. Referente al impacto de la IA sobre la ocurrencia de asistencia al parto, actualmente existen en el mercado una gran variedad de sementales con diferentes características de conformación, incluyendo la facilidad de parto $^{(35,36)}$. Estos resultados sugieren que los productores en las regiones en estudio pudieran estar seleccionando sementales con base a la facilidad de parto (comunicación personal, MC. Fernando Villaseñor). Aunado a esto, los animales en establos que utilizan la IA tienen un menor riesgo de sufrir Retención de Placenta (Cuadro 4). La asistencia al parto es uno de los factores de riesgo a nivel de individuo más importantes asociados con retención de placenta ${ }^{(37)}$. Por lo tanto, es razonable pensar que con la IA se reduzca la prevalencia de asistencias al parto y en consecuencia las retenciones de placenta. Por otra parte, las vacas en los establos con seroprevalencia alta de IBR tienen un menor riesgo de sufrir retención de placenta. Este resultado pudiera parecer contradictorio porque IBR ha sido asociado a aborto y retención de placenta ${ }^{(38)}$. Sin embargo, una posible explicación radica en que las vacas incluidas en nuestro estudio tengan anticuerpos de origen vacunal $^{(18)}$; reduciendo la incidencia de abortos por IBR y en consecuencia disminuyendo el riesgo de sufrir retención de placenta ${ }^{(39)}$.

Las vacas en los establos que utilizan IA tuvieron $142 \%$ más probabilidad de tener DPS > 70 . Desde un punto de vista reproductivo, el éxito al implementar esta tecnología depende de la eficiencia en la detección de estros ${ }^{(40)}$. Aunque en el presente estudio no fue determinado, en los establos de producción de leche a pequeña escala en México ${ }^{(12)}$ y en establos intensivos es común que exista una deficiente tasa de detección de estros ${ }^{(41)}$. Las vacas en establos con seroprevalencias altas de IBR y BVD tuvieron 32 y $86 \%$ más probabilidad de tener DPS > 70; pudiendo ir en IBR desde una reducción en la probabilidad del $5 \%$ hasta un incremento del $80 \%$. Las consecuencias reproductivas de la infección con BVD han sido documentadas $^{(42,43)}$. De acuerdo con nuestro conocimiento, no existen reportes que hayan asociado seroprevalencias altas de estas enfermedades con días a primer servicio. Además, desde un punto de vista patológico, no está claro cómo estas enfermedades pudieran incrementar DPS $>70$. Una posible explicación radica en que la seroprevalencia alta de estas enfermedades pudiera impactar de forma indirecta a este indicador ${ }^{(44)}$. Por ejemplo, seroprevalencias altas de IBR y BVD pudieran estar correlacionadas con otros factores de riesgo como alto grado de estabulación o mal manejo de desechos biológicos ${ }^{(45)}$.

Por otra parte, las vacas en establos que brindan IA tuvieron $32 \%$ más probabilidad de tener DA>110; este cambio puede ir desde una reducción en la probabilidad de $1 \%$ hasta incremento del $80 \%$. Desde un punto de vista de desempeño reproductivo, esta tecnología para el mejoramiento genético también repercute negativamente en indicadores como días a primer servicio, sugiriendo la existencia de deficiencias en la detección de estros ${ }^{(12,46)}$. Para contrarrestar esto, en los establos intensivos de producción de leche se han implementado protocolos de sincronización de estros ${ }^{(47)}$. Considerando la buena fertilidad a primer servicio en este sistema (49.5\%), la implementación de protocolos de inseminación a tiempo fijo 
adaptados específicamente para este sistema de producción pudiera ser una estrategia para mejorar el desempeño reproductivo ${ }^{(48)}$.

Las vacas en establos con 33 o más vacas tuvieron $69 \%$ más probabilidad para NG1S. En otros sistemas de producción, se ha reportado que conforme los establos incrementan su tamaño, la capacidad para manejar reproductivamente al hato disminuye ${ }^{(14-16)}$. En el sistema de producción de leche a pequeña escala, aunque son de menor tamaño comparados con los establos intensivos, el efecto de tamaño de hato es también evidente para este indicador. Por otra parte, se ha reportado que la BVD provoca muertes embrionarias tempranas y subfertilidad en ganado lechero ${ }^{(49-51)}$. Los resultados indican que hatos con seroprevalencia alta de BVD tienen menor riesgo de NG1S, un resultado que pudiera parecer contradictorio. Sin embargo, una posible explicación es que la alta seroprevalencia en estos establos se deba a anticuerpos vacunales ${ }^{(18)}$.

La IA es un factor significativo común para la mayoría de los eventos de interés. El uso de esta tecnología para el mejoramiento genético reduce la prevalencia de problemas posteriores al parto sin afectar la fertilidad a primer servicio, sin embargo, incrementa los días a primer servicio y los días abiertos (probablemente por deficiencias en la detección de estros). Una posible estrategia para aprovechar las ventajas de la IA pudiera ser la implementación de protocolos de sincronización a tiempo fijo para el primer servicio con semen sexado considerando la buena fertilidad observada en los hatos pertenecientes a este sistema de producción. Sin embargo, son necesarios estudios de factibilidad financiera para poder realizar recomendaciones a gran escala en el sector.

Finalmente, una limitación del presente estudio es la incertidumbre acerca del origen de los anticuerpos en las pruebas serológicas. En la base de datos no se contó con antecedentes de vacunación confiables por la falta de disciplina que existe en este tipo de establos para llevar registros. A pesar de que en las regiones estudiadas es común la vacunación ${ }^{(13,18)}$, esta incertidumbre limita la posibilidad de hacer inferencias más precisas con base en los resultados de este estudio. Sin embargo, se considera que la interpretación de los resultados es conservadora y aún fundacional para estudios posteriores en términos epidemiológicos y patológicos.

\section{Conclusiones e implicaciones}

En conclusión, la IA, el tamaño del hato y las seroprevalencias altas de neosporosis, IBR y BVD son factores asociados al desempeño reproductivo en establos pertenecientes al sistema de producción de leche a pequeña escala en México. Los factores de riesgo identificados para asistencia al parto fueron hatos con 33 o más vacas y neosporosis alta; para DPS $>70$ fueron IA y seroprevalencias altas de IBR y BVD; para DA>110 fue IA; para NG1S fueron hatos con 33 o más vacas; para retención de placenta no se identificaron factores de riesgo. Además, el presente estudio es un recordatorio sobre la vital importancia de prevenir neosporosis, IBR y BVD debido a que estas enfermedades están ampliamente distribuidas en 
establos lecheros en el país.

\section{Agradecimientos}

Este trabajo fue financiado por el Fondo Sectorial de Investigación en Materias Agrícola, Pecuaria, Acuacultura, Agrobiotecnología y Recursos Fitogenéticos (SAGARPACONACYT), proyecto 2010-01-144591.

\section{Conflicto de interés}

Los autores declaran que no tienen relaciones financieras o personales que pudieran haber influido inapropiadamente al redactar este artículo.

\section{Literatura citada:}

1. Hemme T, Otte J. Status and prospects for smallholder milk production: a global perspective. Rome: Food and Agriculture Organization of the United Nations (FAO); 2010.

2. SAGARPA. Secretaría de Agricultura, Ganadería, Desarrollo Rural, Pesca y Alimentación. Situación actual y perspectiva de la producción de leche de ganado bovino en México 1900-2000. México. 2004.

3. Barrera Camacho G, Sánchez Brito C. Caracterización de la cadena agroalimentaria nacional e identificación de sus demandas tecnológicas. Leche. Reporte Final Etapa III. Programa Nacional Estratégico de Necesidades de Investigación y de Transferencia de Tecnología Reporte Final Etapa III. Fundación Produce Jalisco. 2003.

4. Hemme T, IFCN (Dairy Team and IFCN Researchers) IFCN Dairy Report 2007, International Farm Comparison Network. IFCN Dairy Research Center, Kiel, Germany.

5. García-Muñiz JG, Mariscal-Aguayo DV, Caldera-Navarrete NA, Ramírez-Valverde $\mathrm{R}$, Estrella-Quintero $\mathrm{H}$, Núñez-Domínguez $\mathrm{R}$. Variables relacionadas con la producción de leche de ganado Holstein en agroempresas familiares con diferente nivel tecnológico. Interciencia 2007;32(12):841-846.

6. Jiménez-Jiménez RA, Espinosa Ortiz V, Soler Fonseca DM. El costo de oportunidad de la mano de obra familiar en la economía de la producción lechera de Michoacán, México. Rev Investig Agrar Ambient (RIAA) 2014;5(1):47-56. 
7. Camacho-Vera JH, Cervantes-Escoto F, Palacios-Rangél MI, Rosales-Noriega F, Vargas- Canales JM. Factores determinantes del rendimiento en unidades de producción de lechería familiar. Rev Mex Cienc Pecu 2017;8(1):23-29.

8. Zamudio BA, Alberti MDP, Manzo F, Sánchez MT. La participación de las mujeres en los sistemas de traspatio de producción lechera en la ciudad de México. Cuad Desarro Rural 2003;(51):37-60.

9. Espinoza-Ortega A, Álvarez-Macías A, del Valle MDC, Chauvete M. La economía de los sistemas campesinos de producción de leche en el Estado de México. Téc Pecu Méx 2005;43(1):39-56.

10. Gröhn YT, Rajala-Schultz PJ. Epidemiology of reproductive performance in dairy cows. Anim Reprod Sci 2000;60-61(Suppl C):605-614.

11. Inchaisri C, Jorritsma R, Vos PLAM, van der Weijden GC, Hogeveen H. Economic consequences of reproductive performance in dairy cattle. Theriogenology 2010;74(5):835- 846.

12. Estrada-Cortés E, Espinosa-Martínez MA, de la Torre-Sánchez JF, VillaseñorGonzález F, Vera-Avila HR, Villagomez-Amezcua E, Montiel Olguín LJ. Factores que influyen en la detección del primer estro post-parto en vacas del sistema familiar en Jalisco [in extenso]. Vamos al campo 2012 Memoria Técnica / Campo Experimental Centro Altos de Jalisco. Tepatitlán, Jalisco. 2012:27-33.

13. Martínez-García CG, Ugoretz SJ, Arriaga-Jordán CM, Wattiaux MA. Farm, household, and farmer characteristics associated with changes in management practices and technology adoption among dairy smallholders. Trop Anim Health Prod 2015;47(2):311-316.

14. Oleggini GH, Ely LO, Smith JW. Effect of region and herd size on dairy herd performance parameters. J Dairy Sci 2018;84(5):1044-1050.

15. Washburn SP, Silvia WJ, Brown CH, McDaniel BT, McAllister AJ. Trends in reproductive performance in Southeastern Holstein and Jersey DHI herds. J Dairy Sci 2018;85(1):244- 251.

16. Dochi O, Kabeya S, Koyama H. Factors affecting reproductive performance in high milk- producing Holstein cows. J Reprod Dev 2010;56(S):S61-65.

17. Fray MD, Paton DJ, Alenius S. The effects of bovine viral diarrhoea virus on cattle reproduction in relation to disease control. Anim Reprod Sci 2000;60:615-627.

18. Milian-Suazo F, Hernandez-Ortiz R, Hernandez-Andrade L, Alvarado-Islas A, DiazAparicio E, Mejia-Estrada F, et al. Seroprevalence and risk factors for reproductive diseases in dairy cattle in Mexico. J Vet Med Anim Health 2016;31;8(8):89-98.

19. Vera AH, Hernandez AL, Espinoza GJ, Ortega RL, Díaz AE, Rompan PH, et al. Producción de leche de bovino en el sistema familiar. Libro Técnico. Veracruz; 2009. 
20. Bijttebier J, Hamerlinck J, Moakes S, Scollan N, Van Meensel J, Lauwers L. Lowinput dairy farming in Europe: Exploring a context-specific notion. Agric Syst 2017;156(Suppl C):43-51.

21. Potter TJ, Guitian J, Fishwick J, Gordon PJ, Sheldon IM. Risk factors for clinical endometritis in postpartum dairy cattle. Theriogenology 2010;74(1):127-134.

22. Biuk-Rudan N, Cvetnić S, Madic J, Rudan D. Prevalence of antibodies to IBR and BVD viruses in dairy cows with reproductive disorders. Theriogenology 2018;51(5):875-881.

23. Mineo TW, Alenius S, Näslund K, Montassier HJ, Björkman C. Distribution of antibodies against Neospora caninum, BVDV and BHV-1 among cows in brazilian dairy herds with reproductive disorders. Rev Bras Parasitol Vet 2006 Oct 1:188-192.

24. Ojeda-Carrasco JJ, Espinosa-Ayala E, Hernández-García PA, Rojas-Martínez C, Álvarez-Martínez JA. Seroprevalencia de enfermedades que afectan la reproducción de bovinos para leche con énfasis en neosporosis. Eco Rec Agro 2016; 3(8):243-249.

25. Garcia-Vazquez Z, Rosario-Cruz R, Ramos-Aragon A, Cruz-Vazquez C, MapesSanchez G. Neospora caninum seropositivity and association with abortions in dairy cows in Mexico. Vet Parasitol 2005;134(1):61-65.

26. Bartels CJM, Wouda W, Schukken YH. Risk factors for Neospora caninumassociated abortion storms in dairy herds in The Netherlands (1995 to 1997) Theriogenology 1999;52(2):247-257.

27. Hobson JC, Duffield TF, Kelton D, Lissemore K, Hietala SK, Leslie KE, et al. Risk factors associated with Neospora caninum abortion in Ontario Holstein dairy herds. Vet Parasitol 2005;127(3):177-188.

28. Magaña-Urbina A, Solorio Rivera JL, Segura-Correa JC. Rinotraqueitis infecciosa bovina en hatos lecheros de la región Cotzio-Téjaro, Michoacán, México. Téc Pecu Méx 2005;43(1):27-37.

29. Solorio Rivera JL. Análisis de riesgo de enfermedades abortivas en el sistema de lechería familiar en la región centro del estado de Michoacán [Tesis doctoral]. México. Universidad Autónoma de Yucatán; 2004.

30. Segura-Correa JC, Solorio-Rivera JL, Sánchez-Gil LG. Seroconversion to bovine viral diarrhoea virus and infectious bovine rhinotracheitis virus in dairy herds of Michoacan, Mexico. Trop Anim Health Prod 2010;42(2):233-238.

31. Pulido-Medellín MO, Díaz-Anaya AM, Andrade-Becerra RJ. Asociación entre variables reproductivas y anticuerpos anti Neospora caninum en bovinos lecheros de un municipio de Colombia. Rev Mex Cienc Pecu 2017;8(2):167-174.

32. Ansari-Lari M, Rowshan-Ghasrodashti A, Jesmani H, Masoudian M, Badkoobeh M. Association of Neospora caninum with reproductive performance in dairy cows: A prospective study from Iran. Vet Res Forum 2017;8(2):109-114. 
33. Mee JF. Prevalence and risk factors for dystocia in dairy cattle: A review. Vet $\mathbf{J}$ 2008;176(1):93-101.

34. Kane SE, Holler LD, Braun LJ, Neill JD, Young DB, Ridpath JF, Chase CCL. Bovine viral diarrhea virus outbreak in a beef cow herd in South Dakota. J Am Vet Med Assoc 2015;246(12):1358-1362.

35. Ali TE, Burnside EB, Schaeffer LR. Relationship Between External Body Measurements and Calving Difficulties in Canadian Holstein-Friesian Cattle. J Dairy Sci 1984;67(12):3034-3044.

36. Abo-Ismail MK, Brito LF, Miller SP, Sargolzaei M, Grossi DA, Moore SS, et al. Genome- wide association studies and genomic prediction of breeding values for calving performance and body conformation traits in Holstein cattle. Genet Sel Evol 2017;49(1):82.

37. Kovács L, Kézér FL, Szenci, O. Effect of calving process on the outcomes of delivery and postpartum health of dairy cows with unassisted and assisted calvings. J Dairy Sci 2016;99(9):7568-7573.

38. Sibhat B, Ayelet G, Skjerve E, Gebremedhin EZ, Asmare K. Bovine herpesvirus-1 in three major milk sheds of Ethiopia: Serostatus and association with reproductive disorders in dairy cattle. Prev Vet Med 2018;150:126-132.

39. Gould S, Cooper VL, Reichardt N, O'Connor AM. An evaluation of the prevalence of Bovine herpesvirus 1 abortions based on diagnostic submissions to five U.S.-based veterinary diagnostic laboratories. J Vet Diagnostic Investig 2013;25(2):243-247.

40. Burnett TA, Madureira AML, Silper BF, Fernandes ACC, Cerri RLA. Integrating an automated activity monitor into an artificial insemination program and the associated risk factors affecting reproductive performance of dairy cows. J Dairy Sci 2018;100(6):5005- 5018.

41. Stevenson JS. Reproductive management of dairy cows in high milk-producing herds. J Dairy Sci 2018;84:E128-143.

42. Grooms DL. Reproductive consequences of infection with bovine viral diarrhea virus. Vet Clin North Am Food Anim Pract 2004;20:5-19.

43. González-Altamiranda EA, Kaiser GG, Mucci NC, Verna AE, Campero CM, Odeón AC. Effect of bovine viral diarrhea virus on the ovarian functionality and in vitro reproductive performance of persistently infected heifers. Vet Microbiol 2013;165:326-332.

44. Szumilas M. Explaining odds ratios. J Can Acad Child Adolesc Psychiatry 2010;19(3):227.

45. De Kruif A. Factors influencing the fertility of a cattle population. J Reprod Fertil 1978;54(2):507-518. 
46. Mottram T. Animal board invited review: Precision livestock farming for dairy cows with a focus on oestrus detection. Animal 2016;10(10):1575-1584.

47. Chebel RC, Al-Hassan MJ, Fricke PM, Santos JEP, Lima JR, Martel CA, et al. Supplementation of progesterone via controlled internal drug release inserts during ovulation synchronization protocols in lactating dairy cows. J Dairy Sci 2010;93(3):922-931.

48. Fricke PM, Carvalho PD, Giordano JO, Valenza A, Lopes G, Amundson MC. Expression and detection of estrus in dairy cows: the role of new technologies. Animal 2014;8(s1):134- 143.

49. Virakul P, Fahning ML, Joo HS, Zemjanis R. Fertility of cows challenged with a cytopathic strain of Bovine Viral Diarrhea virus during an outbreak of spontaneous infection with a noncytopathic strain. Theriogenology 2018;29(2):441-449.

50. Houe H, Pedersen KM, Meyling A. The effect of bovine virus diarrhoea virus infection on conception rate. Prev Vet Med 1993;15(2):117-123.

51. McGowan MR, Kirkland PD, Richards SG, Littlejohns IR. Increased reproductive losses in cattle infected with bovine pestivirus around the time of insemination. Vet Rec 1993;133(2):39-43. 